\section{Dynamics of fish populations}

Fish Population Dynamics. Edited by J. A. Gulland. Pp. xi + 372. (Wiley-Interscience: London and New York, 1977.) £13.50; \$25.

THIS book describes how the dynamics of fish populations can be analysed in terms of the factors affecting their rate of growth, mortality and reproduction, with particular emphasis on the effects of fishing. There are sixteen contributors to the book, including the editor, and many of them have a longstanding international reputation in this field, so much so, that the chapters by Ricker, Gulland, Cushing, Regier, Larkin and Allen, and Chapman are bound to guarantee the book the success it well deserves. It is intended primarily for those already having some interest in fishery science, and for graduates and final-year undergraduates in biology and related subjects. It's form of presentation and style will make it a very 'usable' reference for fishery science undergraduates.

The book has been arranged in three parts. In the first chapter, Ricker describes the historical development of the subject and includes the quantitative methods, of increasing reliability, for describing the direct effects of fishing on stocks of fish and for predicting the catches expected to result from changes in the intensity of fishing or in the sizes of fish caught.

The next section describes some of the particular lines of investigation and methods used in more detail. Because direct observation of fishing in the oceans is difficult and expensive if carried out by special research vessels, scientists have for long depended very much on information from the commercial fisheries; Williams describes the practical problems met in collecting this data. This is a particularly valuable chapter for undergraduates and recent graduates in making them aware of the problems facing the fisheries scientist in obtaining reliable data.

The main lines of analysis as used at present, are reviewed by Gulland, whereas further lines of advance are explored by Rothschild (concerning the concepts of fishing effort and fishing mortality), by Cushing (the problem of the relation between adult stocks and the number of young produced) and by Regier (the position of the fish stock in the whole ecosystem).

The third part of the book looks at how the ideas described earlier have worked out in practice when applied to actual populations. Fish population dynamics grew up in the North Atlantic and North Pacific and much of the work was done on three fish-cod, plaice and the five species of Pacific salmon. The present state of understanding of these species is reviewed by Garrod, Bannister and Larkin, respectively. Population studies and the application of these studies to practical problems, are now worldwide. Murphy looks at the clupeoids, representatives of which are found in most parts of the world, and Rothschild and Suda look at the larger tuna species, most of which are found in all the warmer oceans. The studies reveal how many of the ideas developed in relations to a few fish in northern temperate areas have been usefully applied to very different areas and to very different fish, but Holden shows how some basic differences in the biology of elasmobranchs require some important changes in approach. Finally, Allen and Chapman examine some aspects of the dynamics of whale stocks and in so doing give us a very useful history of whaling.

For those with little understanding of statistics this is not a book to shy away from, as it is most readable and easily understood. It is also not without its lighter moments, as when Gulland (p70), when referring to the difficulty of making direct observations on fish at sea in mid-winter, states that it "involves a large, seaworthy ship costing hundreds of pounds to run. Most fishery research laboratories have one

\section{Continental drift}

Continents in Motion: The New Earth Debate. By Walter Sullivan. Pp. xiv + $399+29$ plates. (Macmillan: London and Basingstoke, 1977; McGraw-Hill: New York, 1974.) £6.95.

This book is aimed at the general intellectual, non-specialist reader and is undoubtedly the best book on continental drift which has yet appeared for this type of market, although its numerous anecdotes and overview makes it interesting reading even for the specialist. It was originally published in the United States in 1974 and, although it is regrettable that it has not been up-dated, the information it contained at that time was so up-todate that subsequent data have only extended and modified certain concepts. This new publication is therefore only slightly dated.

It is a large well produced book and contains 29 colour photographs, although some of these could have been dispensed with and further black-andwhite diagrams inserted. It is written, as would be expected by the Science Editor of the New York Times, in the best journalistic tradition-with an easy style, full of human as well as scientific interest, yet avoiding the slickness and doomwatch aspects which often spoil such books. The drawback for a non-American reader is the emphasis on American findings: most examples are taken from America or American authors, although the British contributions are amply acknowledged. Nevertheless, Arthur Holmes or more specially equipped research vessels to carry out this sea work, but their high running costs and the need to justify their even higher capital costs often cause them to hang like gold-plated albatrosses round the necks of the directors of the laboratories concerned."

In addition, the political aspects of fisheries appear from time to time, as when Larkin (p183) refers to the fact that there is no international agreement that excludes participation of all-comers in the harvesting of salmon beyond narrow coastal limits and, as he says, "at present prices for salmon, it seems only a matter of time before someone decides to test the political wind."

This is a relatively expensive book but is one which the budding fisheries scientist should not be without.

Derek Mills

Derek Mills is Lecturer in Ecology and Fisheries Management in the Department of Forestry and Natural Resources at the University of Edinburgh, $U K$.

still only gets a few lines, whereas the Velikovsky farce receives almost a full chapter.

There are hardly any factual errors and most do not really matter for the audience at which it is aimed, although diagrams of the expected magnetic anomaly patterns in the western Mediterranean should not be portrayed as the actual pattern, even schematically.

I was more disappointed that Sullivan had not really contributed himself, although this is understandable as he has mainly been a bystander. Throughout, however, there was a sneaking feeling that he has already thought of, but not voiced, the questions which the specialists should be asking themselves, but which have not yet been recognised as the real problems.

The poorest coverage is on mechanisms as the concentration is very much on plumes, with brief consideration of the possibility of shallow convection, but virtually no regard to the probable dominant factor, large scale mantlewide convection; but this may merely reflect the reviewer's prejudices! Surprisingly, the metal-ores, other than those of the seafloor, receive little attention, although petroleum and particularly geothermal energy resources are covered. But to ask for more is really a compliment to what has been included.

The book can be unreservedly recommended to the general reader, and even specialists would find $£ 6.95$ could provide them with numerous insights and amusement, even if they learn few new facts.

D. H. Tarling

D. H. Tarling is Senior Lecturer in the Department of Geophysics and Planetary Physics at the University of Newcastle upon Tyne, UK. 